\title{
DIABETES MELLITUS IN A 2-MONTH-OLD CHINESE BABY
}

\author{
BY \\ WONG HOCK BOON \\ From the Paediatric Unit, General Hospital, Singapore
}

(RECEIVED FOR PUBLICATION SEPTEMBER 3, 1956)

Diabetes mellitus in infancy has been reported time and again since the first case was described in 1789, and Schwartzman, Crusius and Beirne (1947) collected all the cases so far reported in the literature and added one of their own. Since then Brodribb, McMurry and Scott (1952) described two further cases and in 1953 Wylie reported a case of congenital diabetes diagnosed in a child aged 17 days. In all the above cases the symptoms which brought the child to hospital had varied from failure to gain weight, polydipsia and polyuria to symptoms as a result of infection, and subsequent investigations had revealed glycosuria and hyperglycaemia. The case to be described presented with a rather unique complaint offered by the mother, namely, an observation that ants were attracted to the wet napkin of the child, although Kitselle (1852) quoted by Schwartzmann et al. (1947) noted honeyed napkins.

\section{Case Report}

S.B.L., a 2-month-old female Chinese infant was referred on September 19, 1955, with a history that the mother had noticed for the previous two weeks that ants used to crowd around the wet napkins; also that the child used to cry excessively before her next feed and was pacified by offering her milk or water. The mother did not notice any change in micturition habits. The patient is the eleventh child in the family, born at full term with a normal delivery and a birth weight of $6 \mathrm{lb}$. The parents and all the other children are alive and well and are free from glycosuria.

On examination, the child was small and weighed $7 \mathrm{lb}$. $12 \mathrm{oz}$. The skin was loose and dry, and further clinical examination did not reveal any other abnormality.

The urine showed orange to red reduction to Benedict's solution with a trace of acetone but no evidence of diacetic acid. An osazone test revealed glucosazone crystals. The fasting blood sugar was $280 \mathrm{mg}$. \% and a glucose tolerance test showed values of $350 \mathrm{mg}$. \% at half an hour, $540 \mathrm{mg} . \%$ at one hour, $560 \mathrm{mg} . \%$ at one and a half hours and $535 \mathrm{mg}$. \% at two hours-a definite diabetic curve. The urine during the test showed orange to red reduction of Benedict's solution with a positive test for acetone in all samples. The microscopical examination of the urine did not reveal any abnormality, and the Mantoux tuberculin test was negative to 1 in 1,000 and 1 in 100 .

The diagnosis of diabetes mellitus in an infant was made and treatment started. From published reports, it was noted that infant diabetics were very sensitive to insulin and it was decided to start the child on 1 unit of soluble insulin before a feed and slowly work up the dose, checking on the blood sugar. On this schedule it was noted that 2 units of soluble insulin before a feed brought the blood sugar down to approximately $120 \mathrm{mg} . \%$ and urine green to Benedict's with no acetone two hours after a feed. When this was achieved, 7 units of insulin zinc suspension (IZS-lente) were given just before the first feed once a day, and the urine tested before each feed. It was found that the first and last specimens usually showed light orange while the other specimens were blue to green. Acetone was absent in all specimens. The child was observed on this schedule for some time and she progressed well. She was fed three hourly, six feeds a day, consisting of reconstituted full-cream dried milk with added dextrimaltose, and the approximate number of calories ingested daily from this milk mixture was 425 .

On October 2, the child had a fit, became drowsy and the hands and feet twitched. The skin was cold and clammy and knee and ankle jerks were increased with bilateral Babinski signs. The pupils were dilated but fundi were normal. A clinical diagnosis of hypoglycaemia was made, the blood for sugar estimation was taken and an intravenous drip of $5 \%$ dextrose in $0 \cdot 2 \%$ sodium chloride was given. The blood sugar was found to be $75 \mathrm{mg}$. \% and urine was blue to Benedict's reagent. The child was finally brought out of the coma after two days and soluble insulin substituted before each feed depending on the urine reaction, and the IZS was finally adjusted to 4 units daily and the child did not give any more trouble. A subsequent glucose tolerance test still showed a diabetic curve.

The child was discharged on December 12, 1955, after the parents had been taught how to inject the IZS each morning and she is still being followed up in the Outpatient Department.

\section{Comments}

The above is probably a case of true pancreatic diabetes and not of transient hyperglycaemia as a 
result of infections or intracranial pathology since the child still shows a diabetic glucose tolerance curve. It has been shown again, as in the above case, that the response of infant diabetics to insulin is capricious, and, in the light of experience of previous writers, the child was started on very small doses of insulin and worked up. Even then, the child had an attack of hypoglycaemic coma when it was thought that she was sufficiently stabilized. She was placed on a régime of IZS because it was considered that frequent injections of soluble insulin would overtax the parents too much and chances of infection would be increased. Apparently, the child responded well to this régime.

Wylie, in her report, noted that diabetes diagnosed under the age of 6 months, after excluding the two cases described by Ramsey (1926) and Lawrence and McCance (1931), where there were only a transient hyperglycaemia with glycosuria, had hitherto claimed a $100 \%$ mortality. Her case survived and is still presumably alive. The child described above is still alive at the time of writing, putting on weight, but the ultimate prognosis is doubtful since her home conditions are really not very satisfactory for giving insulin injections. However, she is being followed up very closely.

\section{Summary}

A case is reported of diabetes mellitus diagnosed at the age of 2 months, and is the first case of infantile diabetes in a Chinese to be reported.

The unusual complaint of attraction of ants by the wet napkin is mentioned.

The method of using IZS in treatment is described.

My thanks are due to the Director of Medical Services, Singapore, for permission to publish this case report and to Dr. C. Elaine Field, child health specialist, General Hospital, Singapore, for advice and encouragement.

\section{REFERENCES}

Brodribb, H. S., McMurry, J. and Scott, L. G. (1952). Brit. med. J., $1,1060$.

Lawrence, R. D. and McCance, R. A. (1931). Archives of Disease in Childhood, 6, 343.

Ramsey, W. R. (1926). Trans. Amer. pediat. Soc., 38, 100.

Schwartzman, J., Crusius, M. E. and Beirne, D. P. (1947). Amer. J. Dis. Child., 74, 587.

Wylie, M. E. S. (1953). Archives of Disease in Childhood, 28, 297. 